九州大学学術情報リポジトリ

Kyushu University Institutional Repository

\title{
Application of high-pressure torsion for consolidation of ceramic powders
}

\section{Edalati, Kaveh}

Department of Materials Science and Engineering, Faculty of Engineering, Kyushu University

Horita, Zenji

Department of Materials Science and Engineering, Faculty of Engineering, Kyushu University

http://hdl. hand le. net/2324/26380

出版情報：Scripta Materialia. 63 (2)，pp.174-177，2010-07. Elsevier バージョン:

権利関係 : (C) 2010 Acta Materialia Inc. 
Scripta Materialia 63 (2010) 174-177

Received 7 March 2010; Accepted 15 March 2010; Available online 18 March 2010

\title{
Application of high-pressure torsion for consolidation of ceramic powders
}

\section{Kaveh Edalati* and Zenji Horita}

Department of Materials Science and Engineering, Faculty of Engineering, Kyushu University, Fukuoka 819-0395, Japan

\begin{abstract}
Alumina $\left(\alpha-\mathrm{Al}_{2} \mathrm{O}_{3}\right)$ powders were successfully consolidated by application of high-pressure torsion (HPT) at ambient temperature and by a subsequent annealing process. Introduction of strain by HPT was confirmed by peak broadening in X-ray diffraction analysis. It was shown that consolidation was greater, giving rise to increased hardness with increasing imposed strain, annealing temperature and annealing time. Scanning electron microscopy showed that consolidation occurred at lower temperatures due to the presence of strain.
\end{abstract}

Keywords: Alumina; Ceramics; High-pressure torsion; Severe plastic deformation.

* Corresponding author. Tel./fax: +81 92802 2992;

e-mail: kaveh.edalati@zaiko6.zaiko.kyushu-u.ac.jp. 
Processing by severe plastic deformation (SPD) has become an attractive research issue in recent years. The grain size is significantly refined through SPD and, consequently, mechanical properties such as hardness and strength are enhanced. Several techniques are available for SPD processing, but high-pressure torsion (HPT) is especially effective in introducing extremely large strains under high hydrostatic pressures and thus it is applicable to hard and less ductile materials such as tungsten [1], magnesium alloys [2] and intermetallics [3].

In the HPT method a thin disc specimen is placed between two massive anvils under high pressure and intense strain is introduced by rotating the two anvils with respect to each other [4]. In addition to grain refinement, HPT is also applicable as a processing tool for consolidation of powders [5-23] such as metallic materials [5-12], metal-ceramic composites [11-17] and amorphous materials [17-23]. The consolidation of metal-ceramic composites was successfully achieved with fractions of ceramics up to as large as $50 \%[15,16]$. However, to the best of the authors' knowledge there appears to have been no application of HPT for the consolidation or pre-compaction of pure ceramic powders, including an examination of the influence of strain on consolidation.

In this study, and for the first time, commercially pure $\alpha-\mathrm{Al}_{2} \mathrm{O}_{3}$ powders were subjected to HPT and subsequently to annealing. The evolution of microhardness and microstructures were investigated, with attention paid to the consolidation process during HPT and post-HPT annealing. Materials used in this study were commercially pure $\alpha-\mathrm{Al}_{2} \mathrm{O}_{3}$ powders of $\sim 1 \mu \mathrm{m}$ particle size. Approximately $0.5 \mathrm{~g}$ of the powders was placed in a flat-bottomed shallow hole of $10 \mathrm{~mm}$ diameter and $0.25 \mathrm{~mm}$ depth located in the center of the lower anvil of a HPT facility. The powders were first pressed by lifting the lower anvil against the upper anvil and both anvils were rotated with respect to each other while pressing. The HPT operation was conducted at room temperature at a rotation speed of $\omega=0.5$ r.p.m. for either $N=2$, 4 or 10 revolutions under a pressure of $P=6 \mathrm{GPa}$. Details concerning the HPT facility have been reported elsewhere [24,25]. The disc samples after processing by HPT were annealed at temperatures of $T=600,1000,1200$ and $1300{ }^{\circ} \mathrm{C}$ for periods of $t=2$ and $16 \mathrm{~h}$. In this annealing an argon atmosphere was used to eliminate atmosphere-induced structural evolution [26]. The appearance of the powders before and after processing by HPT is shown in Figure 1.

The disc samples were evaluated through Vickers microhardness measurements, density measurements, scanning electron microscopy (SEM) and X-ray diffraction (XRD) analysis. First, after processing by HPT the discs were polished and the Vickers microhardness was measured at the center (within $1 \mathrm{~mm}$ of the center, $\mathrm{r}<1 \mathrm{~mm}$ ) at 8 different points and edge ( $>4 \mathrm{~mm}$ from the center, $r>4 \mathrm{~mm}$ ). Second, the sample density was determined by Archimedes' principle using an electronic balance with an accuracy of $0.1 \mathrm{mg}$. Third, SEM at $20 \mathrm{keV}$ was used for microstructural observation of the powders and disc samples. Fourth, structural analyses with XRD were performed using $\mathrm{CuK} \alpha$ radiation at $40 \mathrm{kV}$ and $40 \mathrm{~mA}$ with a scanning step of $0.02^{\circ}$ and a scanning speed of $0.5^{\circ} \mathrm{min}^{-1}$.

It should be noted that the dimensions of HPT processed discs were too small to carry out an evaluation of fracture toughness. 


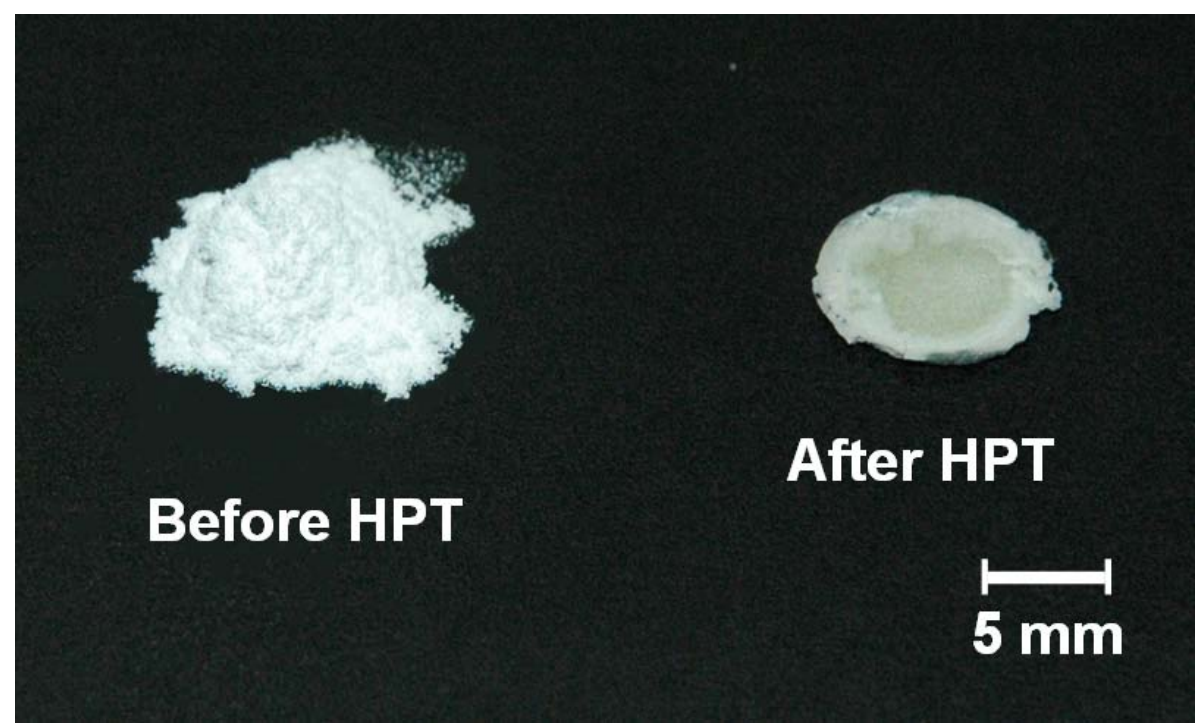

Figure 1. Appearance of alumina powders before (left) and after (right) HPT for 10 revolutions.

Figure 2a plots the microhardness against the number of revolutions at the center and edge of the discs subjected to HPT and subsequent annealing at $1300{ }^{\circ} \mathrm{C}$ for $16 \mathrm{~h}$. The hardness after HPT but without annealing is also plotted in Figure 2a for the edge. For both parts of the discs the hardness increased monotonically with increasing number of revolutions, but the hardness values at the edge were invariably higher than those in the center. This trend can be attributed to the difference in strain, because the magnitude of strain (e) created through HPT varies number of revolutions and distance from the disc center, as given by the following equation [27]:

$$
\varepsilon=\frac{2 \pi r N}{\sqrt{3} t}
$$

where $r$ is the distance from the disc center, $N$ is the number of revolutions and $t$ is the thickness of the disc. Thus, the center of the disc corresponds to a shear strain theoretically equal to zero and undergoes nearly pure compression. Figure 2a suggests that consolidation improves as the strain increases with an increase in the number of revolutions and/or with distance from the disc center. It should be noted that compaction of powders was not feasible by mere application of a pressure, even at $6 \mathrm{Gpa}$, without rotation to induce strain. These observations are consistent with our earlier report concerning the consolidation of amorphous chips using HPT [23].

The effect of imposed strain is more clearly demonstrated in Figure 2b, plotting all hardness values in Figure 2a as a function of the equivalent strain. It is apparent that the hardness after annealing increased with increasing equivalent strain. It should be noted that calculation of the equivalent strain did not take into account the effect of slippage and thickness reduction during HPT processing, because this estimation is difficult for powders [28,29]. Inspection of Figure 2a and b reveals that the increase in hardness with the increase in equivalent strain was $\sim 1.8$ times. However, annealing gave rise to a 10 times increase in hardness when compared with the sample without annealing. Thus, post-HPT annealing plays a crucial role in densification of ceramic powders. 

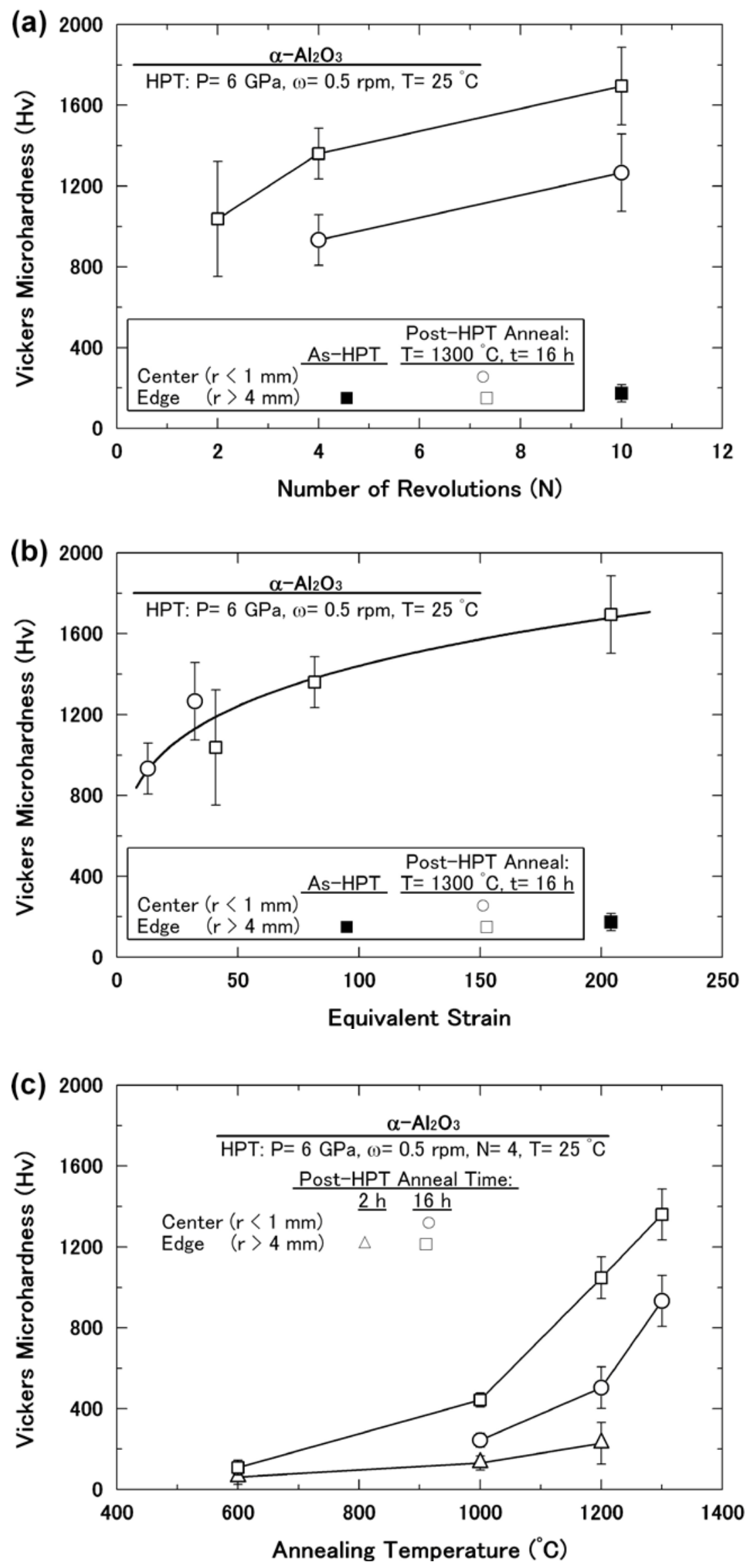

Figure 2. Vickers microhardness plotted against (a) number of revolutions, (b) equivalent strain and (c) annealing temperature at the center and edge of discs. 
Figure 2c plots microhardness as a function of annealing temperature for the HPT processed discs. The plots include hardness values at the center and edge of the discs after annealing for 2 and $16 \mathrm{~h}$. The microhardness increased with increasing annealing temperature and with the longer annealing time. Moreover, hardness values at the edge were higher than those at the center. Thus, provided that the hardness level reflects the degree of consolidation, all these trends suggest that a higher temperature and longer period of annealing, as well as a greater strain, are important in enhancing the consolidation of alumina powders. It is considered that better consolidation occurs because the connectivity of individual powders improves with an increase in annealing time and temperature, as reported earlier [30,31].

The microhardness values reported in the literature for bulk alumina vary over a wide range, 1200-3000 Hv [30-35]. This variation could be due to differences in either the conditions for measuring hardness [32-34], the level of purity of the powders [32], the microstructure [34], the processing conditions [30,31] or a combination of some or all of these. It should be noted that the maximum hardness attained in this study, $1700 \mathrm{Hv}$, is comparable with those reported in the literature [31-34]. Nevertheless, the consolidation temperature used in this study was low and it is suggested that sintering should be accelerated due to the significant strain introduced by HPT prior to heating. Table 1 documents the measured density and relative density for the powders subjected to HPT for 10 revolutions before and after post-HPT annealing at $1300{ }^{\circ} \mathrm{C}$ for a period of $16 \mathrm{~h}$, including the theoretical value. It appears that annealing of the HPT processed sample resulted in increased density and consolidation to a relative density level as high as $98.6 \%$. This relative density is comparable with those reported in the literature [26,30-32].

Figure 3 shows SEM micrographs of the powders (Fig. 3a), the edge of a disc after HPT processing for 10 revolutions in plan view (Fig. 3b) and the edge part in a plan view of a disc after HPT processing for 10 revolutions followed by annealing at $1300{ }^{\circ} \mathrm{C}$ for $16 \mathrm{~h}$ (Fig. 4c). The particle size appears to be $\sim 1 \mu \mathrm{m}$, with a spherical morphology for the as received powders in Figure 3a. The particles were deformed after processing by HPT, as shown in Figure 3b. Although the overall consolidation and connectivity appeared to be weak, consolidation partially occurred even on HPT processing at room temperature, as indicated by the arrow in Figure 3b. Consolidation improved on annealing after HPT, as shown in Figure 3c, but the connectivity of individual particles was still incomplete, so that the gaps were visible in the sample, as indicated by the arrows in Figure 3c.

XRD profiles are shown in Figure 4 for the powders, for the disc subjected to HPT for 10 revolutions and for the disc subjected to HPT for 10 revolutions and annealed at $1300{ }^{\circ} \mathrm{C}$ for $16 \mathrm{~h}$. Neither phase transformation nor impurities were detected in any of the samples within the sensitivity limit of the present XRD analysis. Close examination of Figure 4 indicates that peak broadening occurred appreciably after HPT, but the peak broadening disappeared on annealing after HPT. The appearance of the peak broadening indicates that the HPT process was effective in introducing many of the lattice defects which facilitate the consolidation of alumina powders.

In summary, it is emphasized that HPT processing is promising in pre-compaction and subsequent consolidation of alumina ceramics. Although full consolidation at room temperature cannot be attained in ceramics, unlike metallic materials [5-23], the hardness measurements suggest 
that introducing intense strain under high pressure should be effective for complete consolidation at sintering temperatures as low as $1300{ }^{\circ} \mathrm{C}$ or for shorter sintering time without using binders. It should be noted that the present procedure using HPT contrasts with conventional hot pressing processes where the sintering temperature for a dense alumina sample should be about $1700{ }^{\circ} \mathrm{C}$ $[30,31]$.
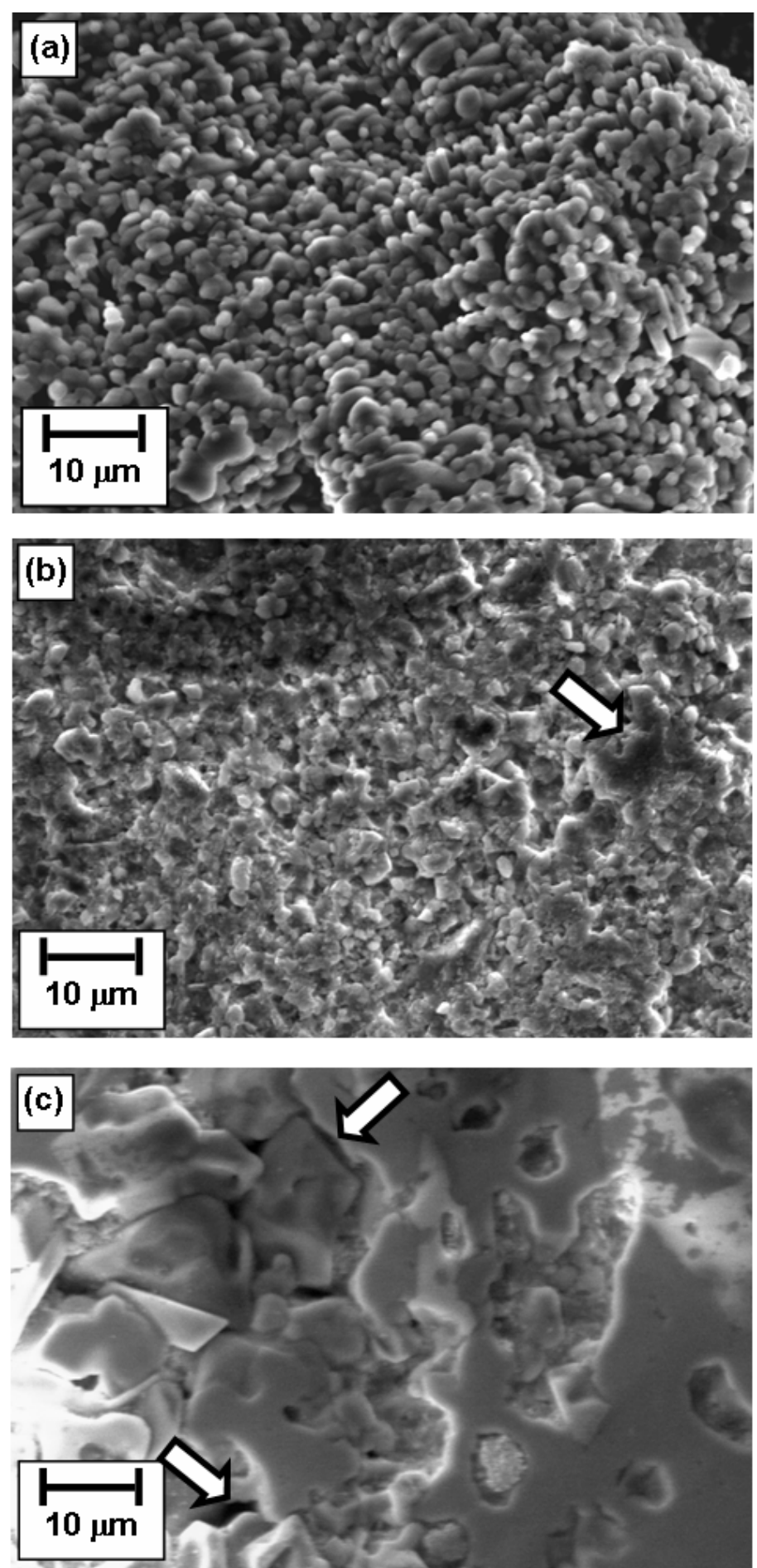

Figure 3. SEM micrographs of (a) powders, (b) edge of disc in plan view after processing by HPT for 10 revolutions and (c) edge of disc in plan view after processing by HPT for 10 revolutions and annealing at $1300{ }^{\circ} \mathrm{C}$ for $16 \mathrm{~h}$. 


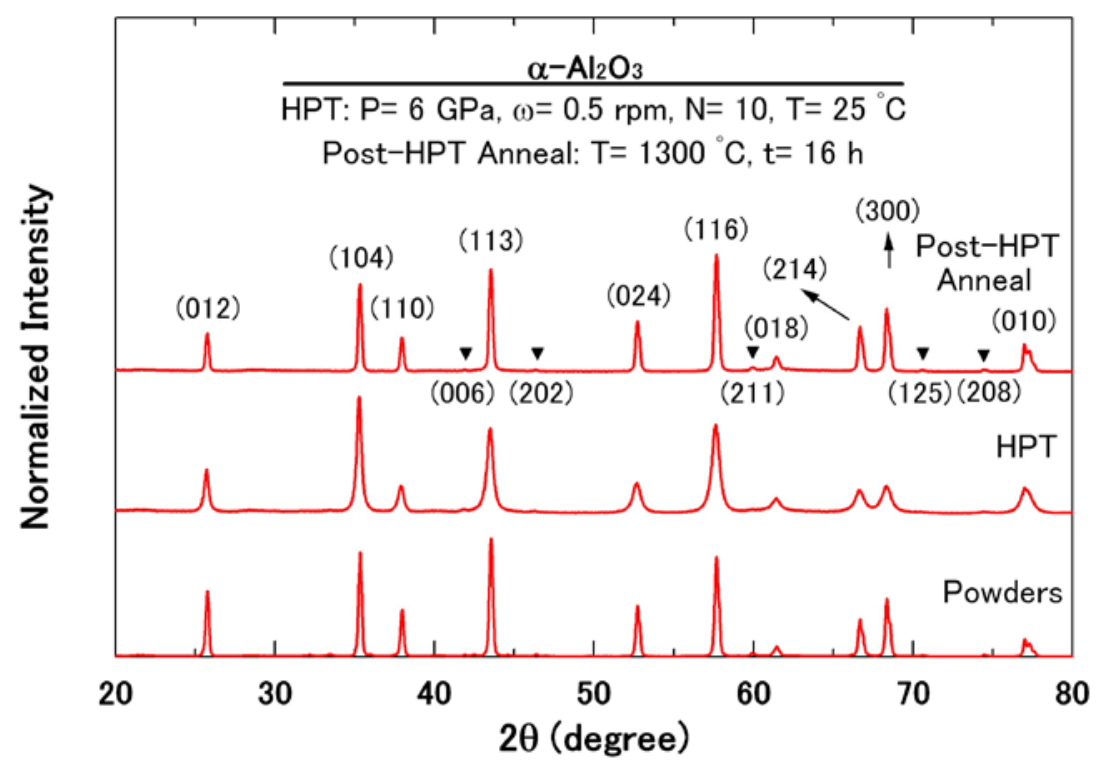

Figure 4. XRD profiles of as received powders, after HPT processing for 10 revolutions and after HPT processing for 10 revolutions and post-HPT annealing at $1300{ }^{\circ} \mathrm{C}$ for $16 \mathrm{~h}$.

Alumina $\left(\alpha-\mathrm{Al}_{2} \mathrm{O}_{3}\right)$ powders were processed by HPT followed by annealing and the following conclusions were made.

1. The powders are consolidated satisfactorily using HPT followed by annealing.

2. XRD analysis reveals that HPT processing is effective in introducing lattice strain in alumina ceramics.

3. Hardness increases and consolidation improves with increasing strain imposed by HPT.

One of the authors (K.E.) thanks the Islamic Development Bank for its support through a scholarship. This work was supported in part by a Grant-in-Aid for Scientific Research from the Ministry of Education, Culture, Sports, Science and Technology of Japan in the Priority Area 'Giant straining process for advanced materials containing ultra-high density lattice defects' and in part by Kyushu University Interdisciplinary Programs in Education and Projects in Research Development (P\&P).

[1] Q. Wei, H.T. Zhang, B.E. Schuster, K.T. Ramesh, R.Z. Valiev, L.J. Kecskes, R.J. Dowding, L. Magness, K. Cho, Acta Mater. 54 (2006) 4079-4089.

[2] M. Kai, Z. Horita, T.G. Langdon, Mater. Sci. Eng. A 488 (2008) 117-124.

[3] C. Rentenberger, T. Waitz, H.P. Karnthaler, Mater. Sci. Eng. A 462 (2007) 283-288.

[4] P.W. Bridgman, Phys. Rev. 48 (1935) 825-847.

[5] A.V. Korznikov, I. Safarov, D.V. Laptionok, R.Z. Valiev, Acta Metal. Mater. 39 (1991) 3193-3197. 
[6] H. Shen, B. Guenther, A.V. Koanikov, R.Z. Valiev, Nunostruct. Mater. 6 (1995) 385-388.

[7] R.Z. Valiev, R.S. Mishra, J. Groza, A.K. Mukherjee, Scripta Mater. 34 (1996) 1443-1448.

[8] J. Sort, A.P. Zhilyaev, M. Zielinska, J. Nogues, S. Surinach, J. Thibault, M.D. Baro, Acta Mater. 51 (2003) 6385-6393.

[9] Z. Lee, F. Zhou, R.Z. Valiev, E.J. Lavernia, S.R. Nutt, Scripta Mater. 51 (2004) 209-214.

[10] A.P. Zhilyaev, A.A. Gimazov, G.I. Raab, T.G. Langdon, Mater. Sci. Eng. A 486 (2008) 123-128.

[11] I.V. Alexandrov, Y.T. Zhu, T.C. Lowe, R.K. Islamgaliev, R.Z. Valiev, Metall. Mater. Trans. A 29 (1998) 2253-2260.

[12] V.V. Stolyarov, Y.T. Zhu, T.C. Lowe, R.K. Islamgaliev, R.Z. Valiev, Mater. Sci. Eng. A 282 (2000) 78-85.

[13] T. Tokunaga, K. Kaneko, Z. Horita, Mater. Sci. Eng. A 490 (2008) 300-304.

[14] T. Tokunaga, K. Kaneko, K. Sato, Z. Horita, Scripta Mater. 58 (2008) 735-738.

[15] E. Menendez, J. Sort, V. Langlais, A. Zhilyaev, J.S. Munoz, S. Surinach, J. Nogues, M.D. Baro, J. Alloys Compd. 434-435 (2007) 505-508.

[16] E. Menendez, G. Salazar-Alvarez, A.P. Zhilyaev, S. Surinach, M.D. Baro, J. Nogues, J. Sort, Adv. Funct. Mater. 18 (2008) 3293-3298.

[17] W.J. Botta, J.B. Fogagnolo, C.A.D. Rodrigues, C.S. Kiminami, C. Bolfarini, A.R. Yavari, Mater. Sci. Eng. A 375-377 (2004) 936-941.

[18] A.R. Yavari, W.J. Botta, C.A.D. Rodrigues, C. Cardoso, R.Z. Valiev, Scripta Mater. 46 (2002) 711-716.

[19] J. Sort, D.C. Ile, A.P. Zhilyaev, A. Concustell, T. Czeppe, M. Stoica, S. Surinach, J. Eckert, M.D. Baro, Scripta Mater. 50 (2004) 1221-1225.

[20] Z. Kovacs, P. Henits, A.P. Zhilyaev, A. Revesz, Scripta Mater. 54 (2006) 1733-1737.

[21] N. Boucharat, R. Hebert, H. Rosner, R.Z. Valiev, G. Wilde, J. Alloys Compd. 434-435 (2007) 252-254.

[22] T. Czeppe, G. Korznikova, J. Morgiel, A. Korznikov, N.Q. Chinh, P. Ochin, A. Sypien, J. Alloys Compd. 483 (2009) 74-77.

[23] K. Edalati, Y. Yokoyama, Z. Horita, Mater. Trans. 51 (2009) 23-26.

[24] G. Sakai, Z. Horita, T.G. Langdon, Mater. Sci. Eng. A 393 (2005) 344-351.

[25] K. Edalati, T. Fujioka, Z. Horita, Mater. Sci. Eng. A 497 (2008) 168-173.

[26] A.S.A. Chinelatto, R. Tomasi, Ceram. Int. 35 (2009) 2915-2920.

[27] R.Z. Valiev, Y.V. Ivanisenko, E.F. Rauch, B. Baudelet, Acta Mater. 44 (1996) 4705-4712.

[28] K. Edalati, T. Fujioka, Z. Horita, Mater. Trans. 50 (2008) 44-50.

[29] K. Edalati, Z. Horita, T.G. Landgon, Scripta Mater. 60 (2009) 9-12.

[30] C.A. Say, D.A. Earl, M.J. Thompson, Mater. Lett. 53 (2002) 262-267.

[31] P. Rao, M. Iwasa, I. Kondoh, J. Mater. Sci. Lett. 19 (2000) 543-545.

[32] R.D. Rawlings, Mater. Sci. Eng. 61 (1983) L1-L5.

[33] S. Sasaki, J.B. Pethic, Wear 241 (2000) 204-208.

[34] A. Krell, S. Schadlich, Mater. Sci. Eng. A 61 (307) (2001) 172-181.

[35] J.F. Shackelford, W. Alexander, CRC Materials Science and Engineering Handbook, third ed., CRC Press, Boca Raton, FL, 2001. 